\title{
WATER VAPOR COLUMn MEASUREMENTS With INFRARED ACTIVE OPTICAL IPDA LiDAR
}

\author{
Upendra N. Singh ${ }^{1 \dagger}$, Syed Ismail ${ }^{2}$, Tamer F. Refaat ${ }^{3}$ and Mulugeta Petros ${ }^{3}$ \\ ${ }^{1}$ NASA Engineering and Safety Center, NASA Langley Research Center, Hampton, VA 23681, USA \\ ${ }^{2}$ AS\&M Inc., Hampton, VA 23666, USA \\ ${ }^{3}$ Remote Sensing Branch, NASA Langley Research Center, Hampton, VA 23681, USA \\ ${ }^{\dagger}$ Corresponding author, e-mail: upendra.n.singh@nasa.gov
}

\begin{abstract}
Development of a novel triple-pulsed 2- $\mu$ m direct detection Integrated Path Differential Absorption (IPDA) lidar to measure column average carbon dioxide (XCO2) and water vapor (XH2O) from an airborne platform provides a new tool to advance atmospheric science studies. Column water vapor measurements are used in global mapping of weather fronts, weather forecast, and in studies of atmospheric transport, radiation, clouds and climate. Water vapor interference is source of biases in XCO2 measurements due to overlap in absorption, line broadening, and retrieval of dry air mixing of carbon dioxide. Model calculations show a XH2O measurement capability of $0.5 \%$ accuracy over 1.0 km spatial scales from the NASA B-200 aircraft. Ground testing of the integrated IPDA was in progress during December 2017January 2018, and airborne measurements and validation of XH2O measurements over land and ocean are planned during January-February 2018. Technology developments in the measurement of $\mathrm{XH} 2 \mathrm{O}$ are presented along with performance projections, and results from ground and airborne testing and validations in this paper.
\end{abstract}

Keywords-carbon dioxide; water vapor; triple-pulse laser; lidar; DIAL; IPDA

\section{INTRODUCTION}

Lidar is an important tool for profiling atmospheric aerosols, clouds, and molecular species [1]. Lidar systems operating in the 2- $\mu \mathrm{m}$ wavelength region are of special interest due to their many distinctive absorption features for important atmospheric constituents, such as water vapor and carbon dioxide [2]. For the last decade, NASA Langley Research Center (LaRC) has been conducting extensive research for developing laser transmitters, detectors and ground-based 2- $\mu \mathrm{m}$ Differential Absorption Lidar (DIAL) systems for atmospheric $\mathrm{CO}_{2}$ profiling [3-6], and airborne Integrated Path Differential Absorption (IPDA) measurements [7-11]. In this region independent and simultaneous DIAL measurements of $\mathrm{H}_{2} \mathrm{O}$ and $\mathrm{CO}_{2}$ can be made by a careful choice of the operating wavelength.

Measurement of column water vapor using the IPDA lidar technique is the focus of this paper. Water vapor is one of the most important atmospheric trace gas species and influences radiation, climate, cloud formation, surface evaporation, precipitation, storm development, transport, dynamics, and chemistry. Water vapor is one of the two strong greenhouse gases in the atmosphere. Column water vapor measurements are used in global mapping of weather fronts, weather forecast, and in studies of atmospheric transport, radiation, cloud and climate. Water vapor is the vehicle for energy transfer in atmosphere involving, evaporation, condensation and energy transfer. Water vapor changes rapidly in space and time. IPDA technique offers the opportunity to capture these variations.

Measurements of water vapor are also required to reduce the error (bias) in the measurement of other greenhouse gases, such as carbon dioxide, due to the uncertainty in the knowledge of highly variable gas. To the first order, in the IPDA design/development approach, a major error source due to water vapor interference is minimized by operating the instrument on the longer wavelength side of the carbon dioxide R30 line and matching the water vapor absorption at the on-line to that of the off-line. The residual error is reduced by using the IPDA XCO2 measurements. Second, the presence of water vapor causes significant broadening of carbon dioxide absorption lines [12], which depends upon the amount of water vapor in the atmosphere. Third, a knowledge of the amount of water vapor is required for dry-air mixing ratio calculations of the measured gas.

NASA has a strong heritage in the development of DIAL instruments, sub-systems and conducting field experiments to measure atmospheric water vapor [13]. Currently, under the NASA's Earth Science Technology Office (ESTO), Instrument Incubator Program (IIP) we are developing a triple pulsed, 2$\mu \mathrm{m}$ direct IPDA lidar system to demonstrate column average dry mixing ratio of carbon dioxide $\left(\mathrm{XCO}_{2}\right)$ and water vapor (XH2O) measurements independently and simultaneously from an airborne platform. The transmitter is a triple-pulsed laser that operates at $50 \mathrm{~Hz}$, transmitting three wavelengths. This aircraft based system transmits three laser pulses with a time separation of about $200-\mu \mathrm{s}$ at $50 \mathrm{~Hz}$ each. These pulses have about $100 \mathrm{~ns}$ temporal width. This system allows measurements of water vapor column to the ground and above and between broken clouds. In addition, the laser pulses have nearly the same ground foot print, and the lidar signal is the result of the same sampling volume of the atmosphere minimizing effects due to variations in sampling volume and complex terrain effects in the $\mathrm{XH} 2 \mathrm{O}$ measurements.

\section{WAVELENGTH SELECTION AND IPDA TECHNIQUE}

Fig. 1 shows the total integrated vertical optical depth variation with wavelength for atmospheric carbon dioxide and water vapor. Optical depth calculations used the US Standard atmospheric model for metrological profiles and gases mixing ratios, and the HITRAN 2008 for line parameters [14]. IPDA 


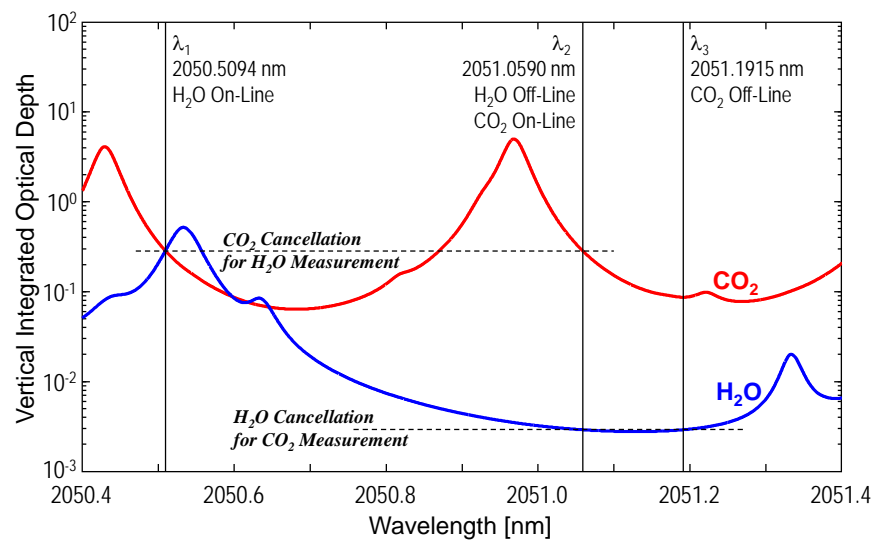

Fig 1. Comparison of the $\mathrm{CO}_{2}$ and $\mathrm{H}_{2} \mathrm{O}$ integrated optical depths for the US Standard model atmosphere. Vertical lines mark the selected wavelengths for the three laser pulses, for simultaneous $\mathrm{CO}_{2}$ and $\mathrm{H}_{2} \mathrm{O}$ measurements.

operation is achieved by proper selection of the wavelengths of the three laser pulses that are transmitted sequentially within the short time intervals. The principle of wavelength selection in this new technique is demonstrated in Fig. 1. The carbon dioxide on-line and off-line wavelengths are selected so that both would have the same amount of water vapor absorption. This eliminates the water vapor absorption interference from the carbon dioxide measurements. Similarly, the water vapor lines are selected to eliminate carbon dioxide interference. Note, however, that both carbon dioxide and water vapor measurements share the same wavelength for the on-line and the off-line, respectively. This approach allows measurement of carbon dioxide and water vapor simultaneously while avoiding interference from each other.

In the IPDA technique, two laser pulses are transmitted through the atmosphere to monitor a specific gas molecule. One laser pulse is tuned to a spectral location that is strongly absorbed by the gas molecule (on-line, $\lambda_{\text {on }}$ ) and the other is tuned to a nearby less absorbing location (off-line, $\lambda_{\text {off }}$ ) for the same molecule. As shown in Fig.1, $\lambda_{1}$ is used as the on-line, and $\lambda_{2}$ is used as the off-line for the measurement of water vapor. Lidar signals reflected by the hard target, either Earth surface or clouds top, are recorded by the IPDA receiver system are calculated using the equation [15]:

$P(\lambda, R)=\eta_{r} \cdot \varphi_{r} \cdot \frac{A}{(R)^{2}} \cdot \frac{E}{t} \cdot \frac{\rho}{\pi} \cdot \exp [-\tau(\lambda)]$

where $\mathrm{P}$ is the detected signal power, $\eta_{\mathrm{r}}$ is the system efficiency, $\varphi_{\mathrm{r}}$ is the overlap function, $\mathrm{A}$ is the effective area of the receiver telescope, $\mathrm{R}$ is the range to the target, $\mathrm{E}$ is the pulse energy, $\mathrm{t}$ is the sampling time, $\rho$ is the reflectivity of the target and $\tau$ the double-path optical depth. The principal measurement from the IPDA signals is the double-path differential optical depth, $\triangle O D$, given by:

$$
\Delta O D \approx \frac{1}{2} \cdot \ln \left(\frac{P_{\text {off }} / E_{\text {off }}}{P_{\text {on }} / E_{\text {on }}}\right)
$$

where, $\mathrm{P}_{\text {off }}$ and $\mathrm{P}_{\text {on }}$, the measured off-line and on-line powers respectively, and $\mathrm{E}_{\text {off }}$ and $\mathrm{E}_{\mathrm{on}}$, are the corresponding transmitted energies.

The weighted-average dry-air volume mixing ratio of water vapor, $\mathrm{XH} 2 \mathrm{O}$, can be retrieved from this measurement using the equation

$$
X_{H 2 O}=\frac{\Delta O D_{H 2 O}}{\int_{P_{A}}^{P_{G}} W F_{H 2 O}\left(\lambda_{\text {on }}, \lambda_{\text {off }}, P, T\right) \cdot d P}
$$

where $\mathrm{WF}_{\mathrm{H} 2 \mathrm{O}}$ is the weighting function for $\mathrm{H}_{2} \mathrm{O}$, obtained from [16].

$W F_{\text {gas }}\left(\lambda_{\text {on }}, \lambda_{\text {off }}, P\right)=\frac{\sigma_{\text {gas }}\left(\lambda_{\text {on }}, P\right)-\sigma_{\text {gas }}\left(\lambda_{\text {off }}, P\right)}{g(P) \cdot\left[m_{d r y}+m_{w v} \cdot \alpha_{w v}(P)\right]}$

where $\sigma$ is the absorption cross section as a functions of pressure and temperature, and $\alpha_{v w}$ is the water vapor mixing ratio.

\section{TRIPLE-PULSE IPDA TECHNOLOGY}

The 2- $\mu \mathrm{m}$ triple-pulse IPDA lidar consists of a laser transmitter, receiver and data acquisition system. The triplepulse IPDA laser transmitters is based on the Ho:Tm:YLF highenergy $2-\mu \mathrm{m}$ pulsed laser technology [3]. The generated 2- $\mu \mathrm{m}$ laser beam is transmitted coaxially with the receiver telescope after beam expansion. Energy monitors, installed inside the laser enclosure, detect and measure the energy of each of the transmitted pulses [9]. The exact wavelengths of the three pulses are controlled by a wavelength control unit.

\begin{tabular}{|c|c|c|c|}
\hline \multirow{9}{*}{ 总 } & $\begin{array}{c}\text { Wavelength } \\
\lambda_{1}=2050.5094 \mathrm{~nm} \\
\lambda_{2}=2051.0590 \mathrm{~nm} \\
\lambda_{3}=2051.1915 \mathrm{~nm}\end{array}$ & $\begin{array}{c}\text { Energy } \\
50 \mathrm{~mJ} \\
15 \mathrm{~mJ} \\
5 \mathrm{~mJ}\end{array}$ & $\begin{array}{l}\text { Pulse Width } \\
30 \mathrm{nsec} \\
60 \mathrm{nsec} \\
100 \mathrm{nsec}\end{array}$ \\
\hline & Repetition Rate & & $50 \mathrm{~Hz}$ \\
\hline & Beam Quality & & $2.0\left(\mathrm{M}^{2}\right)$ \\
\hline & Bean Divergence & & $150 \mu \mathrm{rad}$ \\
\hline & Laser Line-Width & & Transform Limited \\
\hline & Frequency Control A & curacy & $<1 \mathrm{MHz}$ \\
\hline & Spectral Purity & & $99.9 \%$ \\
\hline & Wall-Plug Efficiency & & $2 \%$ \\
\hline & Beam Expansion & & $\mathrm{x} 10$ \\
\hline \multirow{4}{*}{ : } & Optical Efficiency & & $65 \%$ \\
\hline & Telescope Diameter & & $40 \mathrm{~cm}$ \\
\hline & Optical Filter Spectra & Width & $1.6 \mathrm{~nm}$ \\
\hline & Field-of-View & & $300 \mu \mathrm{rad}$ \\
\hline \multirow{5}{*}{ 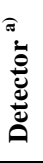 } & Operating Temperatı & & $-20^{\circ} \mathrm{C}$ \\
\hline & Bias Voltage & & $300 \mathrm{mV}$ \\
\hline & Quantum Efficiency & & $67.75 \%$ \\
\hline & Dark Current & & $3.7 \mathrm{nA}$ \\
\hline & Capacitance & & $29.3 \mathrm{pF}$ \\
\hline \multirow{4}{*}{$\stackrel{\tilde{a}}{\mathbb{E}}$} & Gain & & $10^{6} \mathrm{~V} / \mathrm{A}$ \\
\hline & Bandwidth & & $3.5 \mathrm{MHz}$ \\
\hline & Noise Current Spectr & Density & $450 \mathrm{fA} / \mathrm{Hz}^{1 / 2}$ \\
\hline & Noise Voltage Spect & Density & $2.8 \mathrm{nV} / \mathrm{Hz}^{1 / 2}$ \\
\hline \multirow{3}{*}{ 衤 } & Background Solar Irr & liance & $0.5 \mathrm{~mW} / \mathrm{m}^{2} . \mathrm{nm} . \mathrm{sr}$ \\
\hline & Surface Reflectivity & egi/ocean) & $0.09 / 0.08$ \\
\hline & Aircraft Speed & & $100 \mathrm{~m} / \mathrm{s}$ \\
\hline
\end{tabular}

Table 1. Lidar parameter of the baseline IPDA 
In the triple-pulse laser transmitter, the crystal is end pumped using $792 \mathrm{~nm} \mathrm{AlGaAs}$ laser diode arrays. This external pumping targets the Tm, which transfer the stored energy to the Ho relying on the different excitation lifetime. Relative to the pump pulse, Q-switch triggers produces up to three successive laser pulses with relatively controlled energies and pulse-widths. For the same pump energy, higher 2- $\mu \mathrm{m}$ energy is extracted by increasing the number of the output Q-switched pulses [4]. This provides higher optical-to-optical efficiency of the triple-pulse laser as compared to double and single pulse operation modes. In addition, extracting higher optical energy reduces the heat loss in the host crystal and thus relaxes cooling requirement resulting in higher electrical-to-optical efficiency of the laser. Thermal analysis was conducted to design proper heat dissipation out of the laser crystal to avoid performance deterioration or permanent damage.

The exact wavelengths of the pulsed laser transmitter are controlled by the wavelength control unit, which provides the required seeding for each of generated pulses. A study indicated that $\pm 1 \mathrm{MHz}$ on-line wavelength jitter is the dominant transmitter systematic error source using this triple-pulse IPDA lidar for carbon dioxide measurements [17]. This drives the need for a precise wavelength locking mechanism to reduce such error. The design of this unique wavelength control uses a single semiconductor laser diode, obtained from NASA Jet Propulsion Laboratory (JPL) [18] and provides three different seeds of any frequency setting within $35 \mathrm{GHz}$ offset from the locked carbon dioxide R30 line center reference [6]. This unit includes several electronic, optical and electro-optic components which were acquired and characterized at LaRC. Laser diode driver results in a wavelength jitter of $\pm 6.1 \mathrm{MHz}$, which is significantly reduced to $\pm 650.1 \mathrm{kHz}$ using center line locking controller. This meets the jitter limit objective [6]. The wavelength controller is synchronized with the Q-switch trigger pulses to switch the wavelength at the output providing a different wavelength seed for each pulse within the $200 \mu \mathrm{s}$.

The IPDA lidar receiver consists of a $0.4 \mathrm{~m}$ Newtonian telescope that focuses the radiation onto $300 \mu \mathrm{m}$ diameter spot. The telescope secondary mirror is a two surface dichroic flat. One surface turns the return radiation $90^{\circ}$ to the side integrated aft-optics. The opposite surface is used to transmit the expanded laser beam coaxially with the telescope. A single automated mount is used for bore-sight alignment. In the new receiver system design; radiation collected by the telescope is focused, collimated, filtered then applied to a 90/10 beam splitter. The $90 \%$ signal channel is an exact replica of the double-pulsed lidar using an InGaAs pin photodiode detection system. The $10 \%$ channel is planned to be used with an advanced HgCdTe (MCT) electron-initiated avalanche photodiode (e-APD) detection channel. These MCT e-APD devices are in $4 \times 4$ pixel format and are space-qualifiable and were validated for airborne lidar operation at 1.6- $\mu \mathrm{m}$ at NASA Goddard Space Flight Center (GSFC) [19]. In co-ordination with ESTO, LaRC is collaborating with GSFC to integrate this detector into the $2-\mu \mathrm{m}$ IPDA. This e-APD exhibit about $0.5 \mathrm{fW} / \mathrm{Hz}^{1 / 2}$ noise-equivalentpower (NEP) per pixel and is expected to enhance the $2-\mu \mathrm{m}$ IPDA detection performance by expanding the dynamic range and reducing random errors.

\section{IPDA PERFORMANCE MODELING}

Table 2 lists the ground return signals (per shot) at sea-level elevation calculated from the hard target lidar equation (1). The detection system NEP and the background signals, assuming overhead sun, are listed Table 1. Both ocean and vegetation reflectivities are used to estimate the range of signals from ground return. A standard model was used for aerosol transmission calculation at 2- $\mu \mathrm{m}$ wavelength [20]. Table 2 lists the error budget results associated with the optical depth measurement from the aircraft at $8 \mathrm{~km}$ altitude. The total error is a simple combination of systematic and random errors. Atmospheric systematic errors include results from sensitivity analyses for molecular interference; $\pm 1^{\circ} \mathrm{C}$ temperature, \pm 2 mbar pressure and $\pm 20 \%$ relative humidity deviations from the US Standard atmospheric model. Transmitter systematic errors include laser jitter $( \pm 1 \mathrm{MHz})$ and line-width for all three wavelengths. Receiver random error accounts for all noise sources in the detection system including detector and electronics fixed noises and the background and radiation signal shot noises. A 500-shot averaging was included in random error assessment, equivalent to $10 \mathrm{sec}$ average records at $50 \mathrm{~Hz}$ repetition rate. These calculations show a water vapor total error of less than $0.5 \%$. Development of this triple-pulsed IPDA system for carbon dioxide and water vapor measurements and demonstrating its capability advances the technology toward space. Such a system would have the advantage of measuring the two most dominant greenhouse species with one instrument. This would reduce resources and cost for a space-based mission.

Table 2. Lidar signal and error calculations for XH2O measurement.

\begin{tabular}{|lll|}
\hline Power Calculation & Vegetation & Ocean \\
\hline$\lambda_{1}$ Ground Return (W) & $1.23 \mathrm{E}-05$ & $1.09 \mathrm{E}-05$ \\
$\lambda_{2}$ Ground Return (W) & $5.99 \mathrm{E}-06$ & $5.32 \mathrm{E}-06$ \\
Background Signal (W) & $7.11 \mathrm{E}-12$ & $7.11 \mathrm{E}-12$ \\
Noise Equivalent Power (W) & $1.91 \mathrm{E}-06$ & $1.91 \mathrm{E}-06$ \\
$\lambda_{1}$ Signal-to-noise Ratio & $2.49 \mathrm{E}+04$ & $2.25 \mathrm{E}+04$ \\
$\lambda_{2}$ Signal-to-noise Ratio & $1.18 \mathrm{E}+04$ & $1.06 \mathrm{E}+04$ \\
\hline Error Budget & & \\
\hline Atmospheric Systematic Error & $4.73 \mathrm{E}-01$ & $4.73 \mathrm{E}-01$ \\
Transmitter Systematic Error & $4.79 \mathrm{E}-01$ & $4.79 \mathrm{E}-01$ \\
Random Error & $4.78 \mathrm{E}-03$ & $5.18 \mathrm{E}-03$ \\
Total Error & $4.80 \mathrm{E}-01$ & $4.81 \mathrm{E}-01$ \\
\hline
\end{tabular}

\section{Ground Testing AND AIRCRAFT DEMONSTRATIONS}

Major objectives of the triple-pulse 2- $\mu \mathrm{m}$ IPDA lidar technology developments, including transmitter, receiver, and data system, have been completed. The $2-\mu \mathrm{m}$ IPDA lidar was integrated in a trailer for system alignments, optimization and ground testing. These activities started in the late Fall of 2017. Laser has been optimized for operation at the three wavelengths shown in Fig. 1. Although $80 \mathrm{~mJ}$ total energy from all three pulses was demonstrated, the current setting result in lower transmitted energy of about $41 \mathrm{~mJ}$ for risk reduction. This is comparable to the planned goal of $70 \mathrm{~mJ}$ in the baseline system. However, energy reduction does not degrade the overall performance, which is limited by systematic errors of the system in achieving $\mathrm{XH} 2 \mathrm{O}$ total error of less than $0.5 \%$ as shown in Table 2. Ground tests are in progress and show stable operation of the integrated system. Data analysis for retrieval of XH2O uses in situ meteorological data (temperature, pressure, and relative humidity) obtained from the NASA LaRC's Chemistry 
and Physics Atmospheric Boundary Layer Experiment (CAPABLE) site that is located adjacent to the IPDA trailer. Lidar signals, background levels, and signal-to-noise ratio measurements from the ground-based system are consistent with model calculations. The IPDA system is being operated by pointing both horizontally and vertically. In the horizontal mode, lidar signals from a hard target at a distance of about 1 $\mathrm{km}$ uses a variety of surface reflectivities. The IPDA has also been operated in the zenith mode and collected signals from thin cirrus in the mid-to-upper troposphere.

After completing ground testing and system optimization, the IPDA will be integrated onto the NASA B-200 aircraft for conducting airborne tests and instrument validation flights during February-March 2018 from the east coast of the USA. Measurements will be conducted over the land and ocean under a variety of ground conditions, including complex terrain surface, atmosphere, and background conditions. In situ measurement using laser based PICARRO instrument and ground-based radiosonde profiles will be used for the validation of XH2O measurements. Ground tests in progress in January 2018 show capability for column water vapor measurements from the surface to thin clouds with the advanced high sensitivity MCT detection system. This capability will be used to demonstrate $\mathrm{XH} 2 \mathrm{O}$ measurements from the aircraft to the top of the boundary layer to retrieve boundary layer water vapor content. Results of these ground and aircraft measurements of $\mathrm{XH} 2 \mathrm{O}$ will also be presented.

\section{ACKNOWLEDGMENT}

This work was funded and supported by NASA Earth Science Technology Office. The authors acknowledge the support of NASA Jet Propulsion Laboratory and NASA Goddard Space Flight Center.

\section{REFERENCES}

[1] R. Measures, Laser Remote Sensing: Fundamentals and Applications. New York: Wiley, 1984.

[2] R. Menzies and D. Tratt, "Differential laser absorption spectrometry for global profiling of tropospheric carbon dioxide: selection of optimum sounding frequencies for high-precision measurements", Applied Optics, 42, 6569-6577, 2003

[3] U. Singh, B. Walsh, J. Yu, M. Petros, M. Kavaya, T. Refaat, and N. Barnes, "Twenty years of Tm:Ho:YLF and LuLiF laser development for global wind and carbon dioxide active remote sensing”, Optical Materials Express, vol. 5, pp. 827-837 (2015).

[4] U. Singh, T. Refaat, M. Petros, and J. Yu, "Triple-pulse two-micron integrated path differential absorption lidar: a new active remote sensing capability with path to space”, in EPJ Web of Conferences, 27th International Laser Lidar Conference, vol. 119, 02001 (2016).
[5] U. Singh, M. Petros, T. Refaat, and J. Yu, "2-micron triple-pulse integrated path differential absorption lidar development for simultaneous airborne column measurements of carbon dioxide and water vapor in the atmosphere”, Proc. of SPIE, vol. 9879, 987902, 2016.

[6] T. Refaat, M. Petros, C. Antill, U. Singh, and J. Yu, "Wavelength locking to $\mathrm{CO}_{2}$ absorption line-center for $2-\mu \mathrm{m}$ pulsed IPDA lidar application," in Proc. of SPIE, vol. 9879, 2016, no. 987904.

[7] T. Refaat, U. Singh, J. Yu, M. Petros, R. Remus, and S. Ismail, “Doublepulse $2-\mu \mathrm{m}$ integrated path differential absorption lidar airborne validation for atmospheric carbon dioxide measurement,” Appl. Opt., vol. 55, no. 15, pp. 4232-4246, May 2016.

[8] J. Yu, M. Petros, U. Singh, T. Refaat, K. Reithmaier, R. Remus, and W. Johnson, "An airborne 2- $\mu \mathrm{m}$ double-pulsed direct-detection lidar instrument for atmospheric CO2 column measurements", J. Atmospheric Ocean. Technol., vol. 34, pp. 385-400, Feb. 2017.

[9] T. Refaat, U. Singh, M. Petros, R. Remus, and J. Yu, "Self-calibration and laser energy monitor validation for a double-pulsed $2-\mu \mathrm{m} \mathrm{CO} 2$ integrated path differential absorption lidar application,” Appl. Opt., vol. 54, no. 24, pp. 7240-7251, Aug. 2015.

[10] U. Singh, J. Yu, M. Petros, T. Refaat, R. Remus, J. Fay, and K. Reithmaier, "Airborne 2-micron double-pulsed integrated path differential absorption lidar for column CO2 measurement," in Proc. of SPIE, vol. 9246, 2014, no. 924602.

[11] T. Refaat, U. Singh, J. Yu, M. Petros, S. Ismail, M. Kavaya, and K. Davis, "Evaluation of an airborne triple-pulsed $2 \mu \mathrm{m}$ IPDA lidar for simultaneous and independent atmospheric water vapor and carbon dioxide measurements,” Appl. Opt., vol. 54, no. 6, pp. 1387-1398, Feb. 2015.

[12] C. J. Wallace, C. Jeon, C. N. Anderson, and D. K. Havey, "H2O Broadening of a CO2 line and its nearest neighbors near 6360 cm-1,” J. Phys. Chem. A 115, 13804-13810 (2011).

[13] S. Ismail, R. Ferrare, E. Browell et al., "LASE measurements of water vapor, aerosol, and cloud distributions in Saharan air layers and tropical disturbances.” Journal of Atmospheric Science, 67, 1026-1047, 2010.

[14] L. Rothman, I. Gordon, A. Barbe, D. Benner, M. Birk, V. Boudon, et al., "The HITRAN 2008 molecular spectroscopic database", Journal of Quantitative Spectroscopy and Radiative Transfer, 110, 533-572, 2009.

[15] G. Ehret, C. Kiemle, M. Wirth, A. Amediek, A. Fix, and S. Houweling,"Space-borne remote sensing of $\mathrm{CO} 2, \mathrm{CH} 4$ and N2O by integrated path differential absorption lidar: a sensitivity analysis," Appl. Phys. B 90, 593-608 (2008).

[16] C. Kiemle, M. Quatrevalet, G. Ehret, A. Amediek, A. Fix and M. Wirth, "Sensitivity studies for a space-based methane lidar mission", Atmospheric Measurement Techniques, 4, 2195-2211, 2011.

[17] U. Singh, T. Refaat, S. Ismail, K. Davis, S. Kawa, R. Menzies, and M. Petros, "Feasibility study of a space-based high pulse energy $2 \mu \mathrm{m} \mathrm{CO} 2$ IPDA lidar,” Appl. Opt., vol. 56, no. 23, pp. 6531-6547, Aug. 2017.

[18] M. Bagheri, G. Spiers, C. Frez, S. Forouhar, and F. Aflatouni, "Linewidth measurement of distributed-feedback semiconductor lasers operating near $2.05 \mu \mathrm{m}$," IEEE Photon. Technol. Lett., vol. 27, no. 18, pp. 1934-1937, Sep. 2015.

[19] X. Sun, J. Abshire, and J. Beck, "HgCdTe e-APD detector arrays with single photon sensitivity for space lidar applications”, Proc. SPIE, vol. 9114, 91140K (2014). 